\title{
Right or Wrong, Familiar or Novel in Pictorial List Discrimination Learning
}

\author{
Gudrun Melsbach, Martina Siemann, and Juan D. Delius
}

Experimental Psychology, University of Konstanz, Germany

\begin{abstract}
The interaction between nonassociative learning (presentation frequencies) and associative learning (reinforcement rates) in stimulus discrimination performance was investigated. Subjects were taught to discriminate lists of visual pattern pairs. When they chose the stimulus designated as right they were symbolically rewarded and when they chose the stimulus designated as wrong they were symbolically penalised. Subjects first learned one list and then another list. For a "right" group the pairs of the second list consisted of right stimuli from the first list and of novel wrong stimuli. For a "wrong" group it was the other way round. The right group transferred some discriminatory performance from the first to the second list while the control and wrong groups initially only performed near chance with the second list. When the first list involved wrong stimuli presented twice as frequently as right stimuli, the wrong group exhibited a better transfer than the right group. In a final experiment subjects learned lists which consisted of frequent right stimuli paired with scarce wrong stimuli and frequent wrong stimuli paired with scarce right stimuli. In later test trials these stimuli were shown in new combinations and additionally combined with novel stimuli. Subjects preferred to choose the most rewarded stimuli and to avoid the most penalised stimuli when the test pairs included at least one frequent stimulus. With scarce/scarce or scarce/novel stimulus combinations they performed less well or even chose randomly. A simple mathematical model that ascribes stimulus choices to a Cartesian combination of stimulus frequency and stimulus value succeeds in matching all these results with satisfactory precision.
\end{abstract}

Key words: list discrimination, learning, model, verbal, pictorial, stimuli, frequency, familiarity, novelty, reinforcement, humans

\section{Introduction}

As the understanding of the neurobiological basis of learning and memory has made considerable progress in recent years, the relationship between nonassociative and associative forms of learning has regained interest. Studies on neural connectivity modifications indicate that there is an important interaction between these two kinds of learning inasmuch as both appear to rely on transmission efficacy changes

The research was supported by grants from the Deutsche Forschungsgemeinschaft (Bonn). G. Melsbach received a grant from the Landesgraduiertenprogramm, Baden-Württemberg. We thank K. Borchert, R.-P. Gebhard, D. Lüken, K. Lindlar, and I. Krug for assistance; Profs. I. Naith (Purdue University) and M. Hammerl (Düsseldorf University) for useful hints; and Dr. J. Delius (Max Planck Institute for Human Development, Berlin) for manuscript editing. occurring at the same glutamatergic synapses (Delius \& Delius, 2002). Behaviorally, however, the interactions between nonassociative and associative types of learning have only received minor attention during recent times. However, in earlier times many studies on human verbal list discrimination learning were much concerned with this issue. Departing from animal research that was partly inspired by the above neurobiological findings, we found it desirable to re-examine list discrimination learning in human subjects using pictorial stimuli. The outcome has been the development of a mathematical model capable of capturing, in a simple way, the combined role that stimulus presentation frequencies and stimulus reinforcement rates have in determining discrimination performances.

To introduce the concrete issue, we first describe an animal discrimination experiment. Fersen and Delius (1989) taught pigeons to discriminate 100 fre- 
quently presented stimuli defined as right $\left(f_{\mathrm{r}}\right)$ from 625 scarcely presented stimuli defined as wrong $\left(\mathrm{s}_{\mathrm{w}}\right.$; we use scarce rather than rare because the abbreviation of the latter term would be identical to that of right). The stimuli were visual patterns presented in successive pairs on two pecking keys. The different $\mathrm{f}_{\mathrm{r}}+$ stimuli occurred about six times as often as the $\mathrm{s}_{\mathrm{w}}-$ stimuli. The birds were rewarded $(+)$ if they pecked the $f_{r}+$ stimulus and were penalized $(-)$ if they pecked the $\mathrm{s}_{\mathrm{w}}-$ stimulus. Once the pigeons made less than $25 \%$ choice errors they were confronted with three different test lists, each containing 50 stimulus pairs. The pairs of the control (C) list consisted of new stimuli, half of which were arbitrarily designated as $\mathrm{n}_{\mathrm{r}}$ and the remainder were designated as $\mathrm{n}_{\mathrm{w}}$. The pairs of the "right" (R) list were each composed of an old $f_{r}$ stimulus and a new $n_{w}$ stimulus whereas the pairs of the "wrong" (W) list were each composed of a $n_{r}$ stimulus and a $S_{w}$ stimulus. Choices within these interspersed test pairs were neither rewarded nor penalised (o).

The experiment was designed along reinforcement learning principles. According to these, rewards would progressively increase and penalties would progressively decrease the response eliciting value $v$ of the $\mathrm{r}$ and $\mathrm{w}$ stimuli. In terms of an extremely simple model, choice responses were expected to bring about either a $v_{\mathrm{r}} \leftarrow v_{\mathrm{r}}+1\left(\mathrm{f}_{\mathrm{r}}+\right.$ stimuli) or a $v_{\mathrm{w}} \leftarrow v_{\mathrm{w}}-1\left(\mathrm{~s}_{\mathrm{w}}-\right.$ stimuli) value update. The response eliciting value of unreinforced $n$ stimuli was assumed to be close to zero. The probability of choosing one or the other stimulus out of a pair was expected to be determined by the magnitude of the currently valid $v_{\mathrm{r}}-v_{\mathrm{w}}$ difference. The model obviously explained why the pigeons learned to prefer the $\mathrm{f}_{\mathrm{r}}$ stimuli over the $\mathrm{s}_{\mathrm{w}}$ stimuli during the training. It also explained why the $C$ list $n_{r} O n_{w}$ o pairs yielded chance-level choices (49\% "erroneous" choices) and why the W list $\mathrm{n}_{\mathrm{r}} \mathrm{O} \mathrm{s}_{\mathrm{w}} \mathrm{O}$ pairs yielded a $\mathrm{n}_{\mathrm{r}}$ preference (24\% error choices) that was somewhat smaller than the preference for the $f_{r}$ stimuli of the $f_{r}+s_{w}-$ training pairs $(21 \%$ error choices). But contrary to the reinforcement model, the avoidance of the $\mathrm{n}_{\mathrm{w}}$ stimuli of the list $\mathrm{R}_{\mathrm{r}} \mathrm{O} \mathrm{n}_{\mathrm{w}} \mathrm{O}$ pairs (14\% erroneous choices) was significantly stronger than that of the $\mathrm{S}_{\mathrm{w}}$ stimuli of the $\mathrm{f}_{\mathrm{r}}+\mathrm{s}_{\mathrm{w}}-$ pairs (24\% erroneous choices). It seemed that the more familiar $\mathrm{s}_{\mathrm{w}}$ stimuli were somewhat more attractive to the pigeons than the unfamil$\operatorname{iar} \mathrm{n}_{\mathrm{w}}$ stimuli.

Searching for similar results we came across human word list discrimination learning experiments. In 1942, McClelland introduced a verbal learning paradigm and reported results which led to many follow-up studies (Zechmeister \& Nyberg, 1986). His subjects first learned a list of written adjective pairs where the members were arbitrarily designated right and wrong, e.g., $\operatorname{acid}_{\mathrm{r}}, \operatorname{green}_{\mathrm{w}}$. The word pairs were sequentially presented and the subjects had to respond to each pair by calling out the word that they considered right. Correct responses were acknowledged with a bell sound, incorrect ones were not. A 1st list of word pairs was repeatedly presented until the subjects made $25 \%$ or less errors. They then learned a 2 nd list in a similar manner. This list consisted of pairs assembled from a familiar (f) word already present in the 1st list and novel (n) words. For half of the group $\mathrm{R}$ subjects, the $\mathrm{f}$ words were the previous $\mathrm{r}$ words, and the $\mathrm{n}$ words replaced the $\mathrm{w}$ words (e.g., acid $_{\mathrm{r}}$, firm $_{\mathrm{w}}$ ). For the group W subjects, the f words were the previous w words, and the $\mathrm{n}$ words replaced the $\mathrm{r}$ words (e.g., firm $\mathrm{r}$, green $_{\mathrm{w}}$ ). The group $\mathrm{R}$ was found to preferentially choose the $\mathrm{f}_{\mathrm{r}}$ words out of their 2nd list whereas the $\mathrm{W}$ group began by selecting the $f_{w}$ words before gradually learning to prefer the $n_{r}$ words. McClelland suggested that the eventually predominant calling out of the 1st list $r$ words, a form of rehearsal, had resulted in a more frequent exposure to these words and thus in a greater familiarity with them than with the $\mathrm{w}$ words. When the 2nd lists with their $\mathrm{n}$ words were presented, the subjects began choosing the $\mathrm{f}$ word of each pair which for the $R$ group were also the $r$ words and for the $\mathrm{W}$ group were the w words. However, as the W subjects commenced to call out the $n_{r}$ words, these became increasingly familiar and were thus preferred over the only mildly familiar $\mathrm{f}_{\mathrm{w}}$ words. This account represents the sheer (univariate) version of a frequency theory of verbal discrimination learning.

Somewhat different results were obtained by Underwood, Jesse, and Ekstrand (1964; see also Ekstrand, Wallace, \& Underwood, 1966) using a modified method. They also presented written word pairs and had subjects call out the $r$ words, but the feedback was a renewed pair presentation, with the $r$ word now underlined. The R group showed perfect transfer to their 2nd list, whereas the W group showed good but not perfect transfer and had significant difficulties learning their 2 nd list. The $\mathrm{C}$ group that received a 2nd list with all $\mathrm{n}$ words chose randomly at first, but had little difficulty in learning the new list. Note that according to the sheer frequency theory, the W group should initially have chosen the $\mathrm{f}_{\mathrm{w}}$ stimuli in preference to the $\mathrm{n}_{\mathrm{r}}$ stimuli. But they did not quite do that. Ekstrand et al. (1966) proposed that their subjects had either chosen or avoided the $f$ words of the 2nd lists according to whether they had been $\mathrm{r}$ or w words during the 1st list training but that the more frequent commerce with the $f$ words had enhanced the choice of $\mathrm{r}$ words and hampered the avoidance of w words in the 2 nd list. It was assumed that the upon-choice feedback induced both an $\mathrm{r}$ word frequency augmenting rehearsal, but also led to a strengthening (reinforcement) of right or wrong 
labels of the relevant words. This account represents a composite (bivariate) version of the frequency theory of verbal discrimination learning.

Many further studies examined the validity of these theories. One, for example, compared the effect of having different subjects first read a series of words zero, two, or five times within a word learning, free recall task before the words became the $r$ or the w words in discrimination learning lists (Underwood \& Freund, 1968). Another study compared the effect of alternative " $x_{\mathrm{r}}$ is right" or " $\mathrm{y}_{\mathrm{w}}$ is wrong" styles of feedback (Ogus \& May, 1978), and so forth. After reviewing this research, Zechmeister and $\mathrm{Ny}$ berg (1986) concluded that it had shown that humans somehow record the number of times they have perceived, rehearsed, and reproduced particular verbal items, and that this frequency or familiarity information tends to modulate the performance of various tasks, much as posited by the composite frequency theory. Subsequent studies focused on the question of how implicit or explicit the recording of word exposure frequencies was on how these recorded frequencies were coded in memory, and how their retrieval might control responding (e.g., Brown, 1995; Hintzman \& Curran, 1995; Maddox \& Estes, 1997). A separate line of research found that initially emotionally neutral stimuli tend to elicit an emotionally positive attitude after subjects have been repeatedly exposed to them (Zajonc, 1968; Bornstein 1989). Given a choice between such familiar and unfamiliar stimuli, subjects are more likely to approach and to respond to the former than to the latter stimuli (Murphy, Monahan, \& Zajonc, 1995; Reber, Winkielman, \& Schwartz, 1998; Melsbach \& Delius, 2003). This mere exposure effect probably explains why, other things being equal, more frequently experienced words are preferred over less frequently experienced words.

A bivariate, composite frequency account could explain why Fersen and Delius' (1989) pigeons, contrary to mere reinforcement theory, showed a stronger preference for the $\mathrm{f}_{\mathrm{r}}$ stimuli when responding to the $f_{r} O n_{w} O$ test pairs rather than to the $f_{r}+$ $\mathrm{s}_{\mathrm{w}}-$ training pairs: the never previously presented $\mathrm{n}_{\mathrm{w}}$ stimuli could be expected to be more strongly avoided than the more often presented $\mathrm{s}_{\mathrm{w}}$ stimuli. Other research has shown that pigeons, like humans, can indeed memorize the frequencies with which they have experienced individual visual stimuli (Delius, 1985; Macphail \& O'Reilly, 1989). The step from human verbal learning to animal picture learning is furthermore not a major one if one is prepared to accept that feedback signals about the correctness or incorrectness of word choices such as bell sounds or underlined words might function as symbolic reinforcements rather than mere rehearsal initiators. Already in 1974, Kausler drew attention to parallels between human word discrimination learning and animal stimulus discrimination conditioning but without going so far as to propose a mere reinforcement account of verbal learning. With human list learning being plausibly considered as driven by achievement motivation (see Weiner, 1992), the suggestion that word choice feedback signals function as symbolic reinforcers has merits.

The work we now report pursued two goals. One was to find out whether picture list discrimination experiments, like those done with animals but now carried out with human subjects, would yield results that could be compared with word discrimination findings. The other and perhaps more important purpose was to find out whether a mathematical model embodying the aforementioned frequency and reinforcement combination arguments in a simple way would fit the results of these experiments.

\section{Experiment I: Right and Wrong Stimuli Equally Frequent}

This experiment was designed to emulate the classic McClelland (1942) and Underwood et al. (1964) experiments, but used pictorial rather than verbal stimuli, and employed explicit symbolic reinforcement rather than mere informational feedback.

\section{Methods}

\section{Subjects and Apparatus}

Thirty-four subjects (14 men and 20 women) aged between 20 and 35 years (mean: 27 years) participated. They were either fulfilling a course requirement or were paid for participating. The subjects sat at normal viewing and working distance from the monitor and keyboard of a personal computer, which controlled and recorded the experimental events. The computer was programmed so that the subjects had to navigate a human-like figurine through the corridors, doors, and rooms of a fantasy castle with the help of the cursor keys of the keyboard (Siemann \& Delius, 1998). The subjects were given instructions on how to operate the keys in response to the scenes displayed, requested to respond as fast as they could, and enticed to collect as many rewards as they could. However, they were kept naive about the overall design and purpose of the experiment.

\section{Stimuli and Lists}

One hundred and four abstract decorative-geometrical patterns were selected from an existing collection 

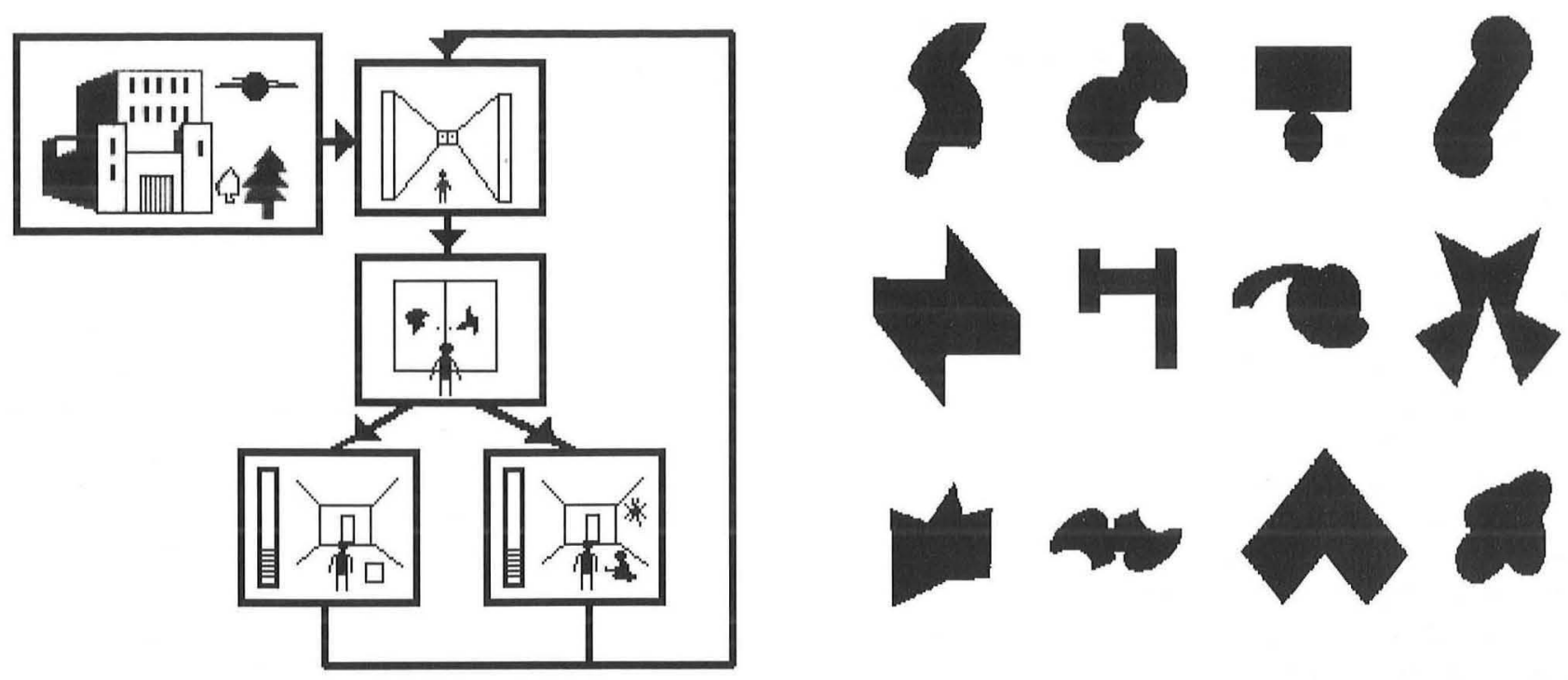

Figure 1. Experiment 1 and 2: Sketch of the computer game paradigm used (left; from Siemann \& Delius, 1998) and examples of the pictorial stimuli employed (right).

(Fersen \& Delius, 1989; see Figure 1). They were chosen to be of roughly equal area, of similar complexity, and to be difficult to name verbally. Presented on the castle doors, the patterns were white on a black background and inscribable in two about $3.5 \mathrm{~cm}$ diameter imaginary circles. Half of the patterns were symmetric, the other half were asymmetric, but since this subdivision had no effect whatsoever on the results, it is henceforth ignored. Apart from a balanced allocation of the symmetric and asymmetric stimuli, the stimuli were randomly divided into two sets of prospectively familiar stimuli $\left(f_{r}\right.$ and $f_{w}$ ) and two sets of prospectively novel stimuli $\left(n_{r}\right.$ and $\left.n_{w}\right)$, each set comprising 26 stimuli. The stimuli from these sets were combined to assemble four different lists of 26 stimulus pairs each: a unique 1st list $\mathrm{f}_{\mathrm{r}}+\mathrm{f}_{\mathrm{w}}-$ and three different 2nd lists $\mathrm{f}_{\mathrm{r}}+\mathrm{n}_{\mathrm{w}}-$, $\mathrm{n}_{\mathrm{r}}+\mathrm{f}_{\mathrm{w}}-$, and $\mathrm{n}_{\mathrm{r}}+\mathrm{n}_{\mathrm{w}}-$.

\section{Design and Procedure}

Trials during both the training and testing blocks took an identical course. The subjects' pressing the arrow-up key caused the figurine to come up to a pair of doors which displayed a pair of patterns. Subjects indicated their stimulus choice by pressing either the right or left pointing arrow key. The leftright side door allocation of the correct stimuli varied quasi-randomly (Gellermann, 1933). Choices of the door bearing the $\mathrm{r}$ pattern brought the figurine into a treasure chamber, where it collected a coin that was added to a hoard (+), and choices of the door bearing the $\mathrm{w}$ pattern brought the figurine into a horror chamber, where it had to give a coin from the hoard to a beggar (-). Choices of $\mathrm{r}$ or $\mathrm{w}$ words were also followed by a sound of either increasing or decreasing pitch lasting about $1 \mathrm{sec}$. The presentation of all 26 stimulus pairs of a list constituted a block of trials. Within blocks the stimulus pairs constituting a list were presented in ever changing random sequences.

All subjects were first all trained with the same $1 s t f_{r}+f_{w}-$ list. Training continued until the subjects reached a criterion of $20 \%$ or less error choices within a block of trials or until they had gone through 12 blocks of training without achieving it. In the latter case, the subjects were excluded from further participation. The successful subjects were then confronted with one of the three alternative 2 nd lists. For this the subjects were allocated to three groups. The control $(\mathrm{C})$ group received the list consisting of pairs made up of all novel stimuli $n_{r}+n_{w}-$. The right (R) group received the list consisting of pairs comprising ordinary $r$ and novel $w$ stimuli, $\mathrm{f}_{\mathrm{r}}+\mathrm{n}_{\mathrm{w}}-$. The wrong (W) group received the list consisting of pairs of novel $r$ and ordinary $w$ stimuli, $n_{r}+f_{w}-$. These 2nd lists were trained until the subjects reached a criterion of no more than $20 \%$ incorrect choices.

Performance Evaluation. The number of blocks needed by each subject to achieve the $20 \%$ error criterion with each of the lists was recorded. Also the total number of times the subjects chose the $r$ stimuli and were rewarded, or respectively penalized for choosing the w stimuli, was recorded. The percent choice error rates and median reaction times of the last block with the 1st list and the first block of the 2 nd lists were computed for each subject. From these individual data we calculated group means. Because 
Table 1. Experiment 1: Mean Blocks to Criterion with 1st list and 2nd list, Mean Errors in Percent and Mean Latencies in Seconds During the Last Block with 1st List and the First Block With 2nd List for Subject Groups $\mathrm{R}, \mathrm{W}$, and $\mathrm{C}$

\begin{tabular}{lcccccc}
\hline & \multicolumn{2}{c}{ Group R, $n=10$} & \multicolumn{2}{c}{ Group W, $n=11$} & \multicolumn{2}{c}{ Group C, $n=9$} \\
\cline { 2 - 7 } Lists & $1 \mathrm{st}_{\mathrm{r}}+\mathrm{f}_{\mathrm{w}}-$ & $2 \mathrm{nd} \mathrm{f}_{\mathrm{r}}+\mathrm{n}_{\mathrm{w}}-$ & $1 \mathrm{st}_{\mathrm{r}}+\mathrm{f}_{\mathrm{w}}-$ & $2 \mathrm{nd}_{\mathrm{w}}+\mathrm{f}_{\mathrm{w}}-$ & $1 \mathrm{st}_{\mathrm{r}}+\mathrm{f}_{\mathrm{w}}-$ & $2 \mathrm{nd} \mathrm{n}_{\mathrm{r}}+\mathrm{n}_{\mathrm{w}}-$ \\
\hline Blocks to criterion & 9.0 & 3.0 & 7.4 & 4.3 & 8.1 & 5.9 \\
Errors 1st list, first block & 6.9 & 23.1 & 18.2 & 40.6 & 12.8 & 47.0 \\
Latencies 1st list, first block & 1.46 & 1.41 & 1.75 & 2.13 & 1.57 & 1.83 \\
\hline
\end{tabular}

of non-normal data distributions the statistical analyses were carried out with Mann-Whitney U tests, preceded, where appropriate, by Kruskal-Wallis analyses of variance. The use of nonparametric tests also extends to the remainder of the experiments reported here.

\section{Results}

Four subjects who did not achieve the 1st-list learning criterion were excluded. The results relating to the remaining 30 subjects are presented in Table 1 . We first consider the results concerning the last block of the 1st list. Although all groups were trained to the same criterion and of course achieved significantly above-chance $50 \%$ error rates ( $U$ tests, $p \mathrm{~s}<$ 0.001 ), and neither differed significantly in terms of mean blocks to criterion nor in terms of mean latencies, the $\mathrm{C}$ group differed significantly from the $\mathrm{R}$ and $\mathrm{W}$ groups in terms of mean errors $(\mathrm{R}>\mathrm{C}, p<$ 0.05 and $\mathrm{W}>\mathrm{C}, p<0.01$; see Figure 2). Note, however, that the 1st-list learning of group $\mathrm{C}$ was only meant to ensure an adequate learning pre-experience but no specifically transferable knowledge about the stimuli. There were no significant 1 st-list performance differences between the $\mathrm{R}$ and $\mathrm{W}$ groups on any of the measures.

Concerning the initial accuracies with the 2nd list, both the R and W groups, but naturally not the $\mathrm{C}$ group, were significantly above chance $50 \%$ error level ( $p$ s $<0.05$ or $<0.01)$. The $\mathrm{R}$ group's performance, furthermore, was significantly superior to the $\mathrm{C}$ and $\mathrm{W}$ group on two measures each; that is choice accuracy $(\mathrm{R}<\mathrm{C}, p=0.001 ; \mathrm{R}<\mathrm{W}, p<0.01$; see Figure 2), blocks to criterion ( $\mathrm{R}<\mathrm{C}, p<0.05)$, and latencies $(\mathrm{R}<\mathrm{W}, p<0.05 ; \mathrm{R}<\mathrm{C}, p<0.05)$. The $\mathrm{W}$ group did not differ significantly from the $\mathrm{C}$ group on any of the three performance measures.

Informal interviews after the experiment indicated that because of the time pressure subjects had been unable to name the stimuli and had not engaged in any form of rehearsal (see Watkins, Peynircioglu, \& Brems, 1984).

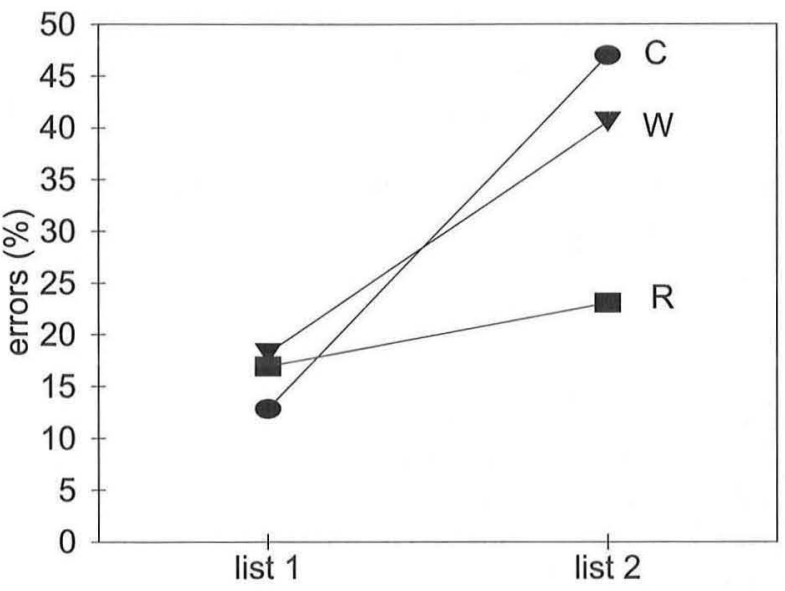

Figure 2. Experiment 1: Errors in percent during the last block with the 1st list and the first block with the 2nd list for groups R, W, and C.

Table 2. Experiment 1: Mean Number of Presentations and Reinforcement Per Right and Wrong Stimuli During 1st-List Learning for Groups R, W, and $\mathrm{C}$.

\begin{tabular}{lcccc}
\hline Group & Present $\mathrm{f}_{\mathrm{r}}$ & Reward $\mathrm{f}_{\mathrm{r}}$ & Present $\mathrm{f}_{\mathrm{w}}$ & Penalty. $\mathrm{f}_{\mathrm{w}}$ \\
\hline $\mathrm{R}$ & 9.0 & +5.7 & 9.0 & -3.4 \\
$\mathrm{~W}$ & 7.4 & +4.6 & 7.4 & -2.8 \\
$\mathrm{C}$ & 8.1 & +5.0 & 8.1 & -3.1 \\
\hline
\end{tabular}

Table 2 lists the number of presentations and of reinforcements that the different stimuli underwent during the learning of the 1 st list. The asymmetry in reward and penalty numbers is simply due to the fact that, as discrimination learning progressed, the subjects were more likely to choose the $\mathrm{r}$ stimuli and less likely to choose the w stimuli. 


\section{Experiment 2: Wrong Stimuli More Frequent Than Right Stimuli}

This experiment involved more direct control over the frequency of stimulus experience than the preceding experiment by presenting the $\mathrm{w}$ stimuli twice as often as the $r$ stimuli.

\section{Methods}

Twenty-four subjects (15 female and 9 male) aged between 20 and 35 years (mean: 24 years) took part. The methods used were the same as those employed in the previous experiment, except for some details. Sixty-five pictures selected from the same stimulus pool employed before were used (Figure 1). The stimuli were divided into four sets: an $s_{r}$ and an $n_{r}$ set, both consisting of 26 stimuli each; an $f_{w}$ and an $\mathrm{n}_{\mathrm{w}}$ set, both consisting of 13 stimuli each, and where the $n_{w}$ set was a subset of the $n_{r}$ set. Three lists of 26 stimulus pairs each were assembled in the same way as in Experiment 1, except that they were all combined from $26 \mathrm{~s}_{\mathrm{r}}$ stimuli and only $13 \mathrm{f}_{\mathrm{w}}$ stimuli, these stimuli being used twice according to the schemes $\mathrm{s}_{\mathrm{r}}+\mathrm{f}_{\mathrm{w}}-$ (1st list for both groups), $\mathrm{s}_{\mathrm{r}}+\mathrm{n}_{\mathrm{w}}-$ (2nd list for group $R$ ), and $n_{r}+f_{w}-(2 n d$ list for group W). Within each group the f stimuli were thus presented twice as frequently as the s stimuli. As before, subjects learned to discriminate the pairs of the 1st list until they reached a criterion of no more than $20 \%$ errors or they had completed 12 blocks. Those who had reached the criterion were then switched to learn one of the two 2nd list versions until they again reached the criterion. The data were processed and analyzed in the same manner as in Experiment 1.

\section{Results}

Three participants failed to achieve the preset criterion with the 1st list and were excluded. The results relating to the remaining 21 subjects are shown in

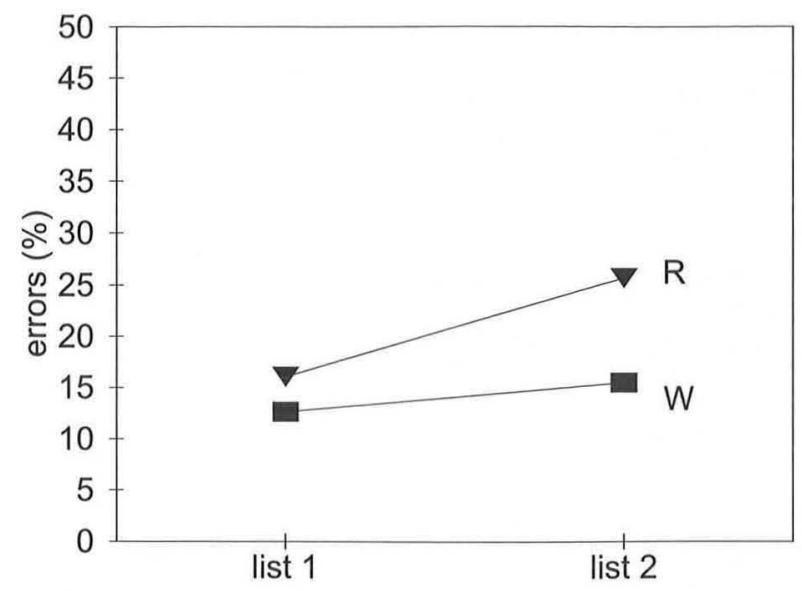

Figure 3. Experiment 2: Errors in percent during the last block with the 1st list and the first block with the 2nd list for groups R and W.

Table 3 and Figure 3. Concerning the 1st list, the two groups exhibited accuracies significantly above chance level $(p s<0.001)$ and did not differ significantly on any of the three performance measures. Both also showed an above chance level accuracy with the 2 nd list $(p s<0.001)$. With this list the W group, however, showed a better performance than the R group on two measures, namely blocks to criterion $(p<0.05)$ and accuracy $(p<0.05)$. Table 4 lists the number of presentations and of reinforcements that the different stimuli underwent during the learning of the 1st list. The reward and penalty numbers were now roughly symmetric but the presentation frequencies were of course markedly asymmetric.

Table 4. Experiment 2: Mean Number of Presentations and Reinforcements (Rewards and Penalties) Per Right and Wrong Stimuli During 1st-List Learning for Groups $\mathrm{R}$ and $\mathrm{W}$

Group Present $r$ Reward $r$ Present w Penalty w

\begin{tabular}{lllll}
\hline $\mathrm{R}$ & 6.8 & +4.4 & 13.6 & -4.9 \\
$\mathrm{~W}$ & 6.0 & +4.0 & 12.0 & -4.0 \\
\hline
\end{tabular}

Table 3. Experiment 2: Mean Blocks to Criterion with the 1st List and 2nd List, Mean Errors in Percent and Mean Latencies in Seconds During the Last Block with 1st List and the First Block With the 2nd List for Subject Groups R and W

\begin{tabular}{lcccc}
\hline & \multicolumn{2}{c}{ Group $\mathrm{R}, n=11$} & \multicolumn{2}{c}{ Group W, $n=10$} \\
\cline { 2 - 5 } Lists & $1 \mathrm{st} \mathrm{s}_{\mathrm{r}}+\mathrm{f}_{\mathrm{w}}-$ & $2 \mathrm{nd} \mathrm{s}_{\mathrm{r}}+\mathrm{n}_{\mathrm{w}}-$ & $1 \mathrm{st} \mathrm{s}_{\mathrm{r}}+\mathrm{f}_{\mathrm{w}}-$ & $2 \mathrm{nd} \mathrm{n}_{\mathrm{r}}+\mathrm{f}_{\mathrm{w}}-$ \\
\hline Blocks to criterion & 6.8 & 2.7 & 6.0 & 1.2 \\
Errors last/first block & 16.1 & 25.5 & 12.7 & 15.4 \\
Latencies last/first block & 1.70 & 1.84 & 1.46 & 1.35 \\
\hline
\end{tabular}




\section{Experiment 3: Right Stimuli More Frequent Than Wrong Stimuli and Vice-Versa}

This experiment pursued the same stimulus frequency issue as the previous ones but used a design more similar to that used by Fersen and Delius (1989). To gauge the influence of verbalization, subjects were confronted with both difficult-to-name stimuli and easy-to-name stimuli.

\section{Method}

Fifteen new subjects ( 5 males, 10 females) aged between 18 and 34 years participated. A simplified, faster version of the computer game of the previous experiments was used. Meanwhile it had become apparent that the motivational props provided by the elaborate but slow castle game were superfluous for the relatively simple discrimination tasks. Stimuli were presented side by side on a computer monitor in pairs about $3.5 \mathrm{~cm}$ apart in black on light blue backgrounds of about $6 \times 5 \mathrm{~cm}$. They remained on the screen until the subjects chose one of the stimuli. Subjects did this by pressing either the right or left cursor key. Upon choice of the correct stimulus during training trials, a virtual coin was added onto a column of coins, the word "right" was displayed and a $300 \mathrm{hz}, 1$-s tone sounded. Upon choice of an incorrect stimulus, a virtual coin was removed from the coin column, the word "wrong" was displayed and a $100 \mathrm{hz}, 3-\mathrm{s}$ tone sounded. During nonreinforced test trials none of these upon-choice feedbacks were given. In all cases, subjects initiated the next trial by pressing the upwards cursor key.

A new collection of 288 pictorial stimuli was assembled (see Figure 4 for examples). Half of these stimuli were concrete pictures that were easy to name and another half were abstract pictures that were hard to name. Each of these sets of 144 stimuli was randomly divided into two subsets $\mathrm{f}_{\mathrm{r}}$ and $\mathrm{f}_{\mathrm{w}}$, each consisting of 8 stimuli, and two subsets $\mathrm{s}_{\mathrm{r}}$ and $\mathrm{s}_{\mathrm{w}}$, each consisting of 48 stimuli, as well as four subsets $(2 \times$ $\mathrm{n}_{\mathrm{r}}$ and $2 \times \mathrm{n}_{\mathrm{w}}$ ), each consisting of 8 stimuli that were to be used in the test phase. The training phase consisted of at most 6 successive blocks, each involving 96 trials with $\mathrm{f}_{\mathrm{r}}+\mathrm{s}_{\mathrm{w}}-$ pair presentations and 96 trials with $\mathrm{s}_{\mathrm{r}}+\mathrm{f}_{\mathrm{w}}-$ pair presentations The corresponding stimuli were randomly assembled into pairs while ensuring that each $\mathrm{s}$ stimulus was presented once and each $\mathrm{f}$ stimulus was presented 6 times. Forty-eight of the pairs were constructed from abstract stimuli and 48 from concrete stimuli. The various pairs were presented in a quasi-randomized order.
When subjects achieved a criterion of $25 \%$ errors or less with all four kinds of stimulus pairs within a block, they were subjected to a test block. It consisted of 192 reinforced training trials, as before, and 128 randomly intercalated, unreinforced test trials (64 with concrete stimuli and 64 with abstract stimuli). The test pairs were constructed by combining the $\mathrm{r}$ and $\mathrm{w}$ stimuli with $\mathrm{n}$ stimuli $\left(\mathrm{f}_{\mathrm{r}} \mathrm{O} \mathrm{n}_{\mathrm{w}} \mathrm{O}, \mathrm{n}_{\mathrm{r}} \mathrm{o} \mathrm{f}_{\mathrm{w}} \mathrm{o}\right.$, $\left.\mathrm{n}_{\mathrm{r}} \mathrm{O} \mathrm{s}_{\mathrm{w}} \mathrm{O}, \mathrm{s}_{\mathrm{r}} \mathrm{O} \mathrm{n}_{\mathrm{w}} \mathrm{O}\right)$ and by combining the different kinds of training stimuli in new ways $\left(\mathrm{f}_{\mathrm{r}} \mathrm{O} \mathrm{f}_{\mathrm{w}} \mathrm{O}, \mathrm{f}_{\mathrm{r}} \mathrm{O}\right.$ $\mathrm{S}_{\mathrm{r}} \mathrm{O}, \mathrm{s}_{\mathrm{w}} \mathrm{O} \mathrm{f}_{\mathrm{w}} \mathrm{O}, \mathrm{s}_{\mathrm{r}} \mathrm{O} \mathrm{s}_{\mathrm{w}} \mathrm{O}$ ), however, without mixing the concrete and abstract stimuli and using each individual stimulus only once. Eight $\mathrm{s}_{\mathrm{r}}$ and $8 \mathrm{~s}_{\mathrm{w}}$ randomly selected stimuli were used during tests. This resulted in 8 pairs of each of the 8 pair types in both an abstract and in a concrete version, which were each presented during a single trial. The assumption was that the subjects would preferentially approach the most rewarded stimuli and avoid the most penalized stimuli with the neither rewarded nor penalized, neutral stimuli falling in between $\left(\mathrm{f}_{\mathrm{r}}>\mathrm{s}_{\mathrm{r}}>\mathrm{n}_{\mathrm{r}} \approx \mathrm{n}_{\mathrm{w}}>\right.$ $\left.s_{w}>f_{w}\right)$. Choices of the first stimulus of each of the pair types listed were accordingly counted as correct. The latencies between pair-display onset and stimulus choice were recorded.

After the test phase was over, the subjects were asked to rate the presentation frequency of stimuli they had seen. All 128 stimuli used in the test trials were individually shown on the computer monitor in a randomized sequence together with a "seldom-frequent" scale displayed beneath. Using the cursor keys subjects positioned a marker on one of the 19 different scale locations. They then entered the marker's position and initiated the presentation of the next stimulus.

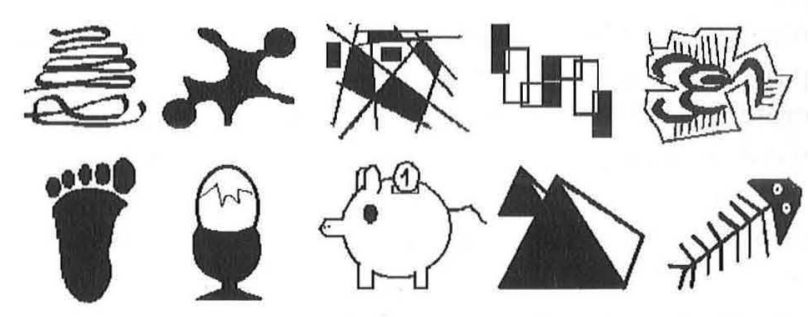

Figure 4. Experiment 3: Stimulus examples; upper row: abstract stimuli, lower row: concrete stimuli.

\section{Results}

One subject had to be excluded because he did not reach the preset learning criterion within the 6 training blocks allowed. The following analyses therefore include the data of the remaining 14 subjects, who on average completed the training within $3.8( \pm 1.0)$ training blocks. As might be expected, the $\mathrm{f}_{\mathrm{r}}+$ 
$\mathrm{s}_{\mathrm{w}}-$ combinations were better learned than the $\mathrm{s}_{\mathrm{r}}+\mathrm{f}_{\mathrm{w}}-$ combinations, and concrete combinations were better learned than abstract ones as judged by the mean errors over all training blocks $\left(\mathrm{f}_{\mathrm{r}}+\mathrm{s}_{\mathrm{w}}-\right.$ concrete, 21.4 $<\mathrm{s}_{\mathrm{r}}+\mathrm{f}_{\mathrm{w}}-$ concrete, $31.9<\mathrm{f}_{\mathrm{r}}+\mathrm{s}_{\mathrm{w}}-$ abstract, $37.2<$ $\mathrm{s}_{\mathrm{r}}+\mathrm{f}_{\mathrm{w}}-$ abstract; 62.3; Page-test, $p<0.01$ ). Table 5 summarizes the mean number of presentations and reinforcements per stimulus classified according to stimulus types during the course of training.

During the test phase the mean error rates and choice latencies associated with these various types of training pairs were again significantly ordered in the same manner $\left(\mathrm{f}_{\mathrm{r}}+\mathrm{s}_{\mathrm{w}}-\right.$ concrete: $1.3 \%, 0.84 \mathrm{~s}<$ $\mathrm{s}_{\mathrm{r}}+\mathrm{f}_{\mathrm{w}}-$ concrete: $4.0 \%, 1.04 \mathrm{~s}<\mathrm{f}_{\mathrm{r}}+\mathrm{s}_{\mathrm{w}}-$ abstract: $8.0 \%, 1.00 \mathrm{~s}<\mathrm{s}_{\mathrm{r}}+\mathrm{f}_{\mathrm{w}}-$ abstract: $14.0 \%, 1.22 \mathrm{~s}$; Pagetests: errors: $p<0.01$; latencies: $p<0.01$ ).

The error rates for the test pairs are shown in the upper panel of Figure 5. In agreement with what was already indicated, the performance with the concrete pairs generally tended to be better than that with the abstract pairs, but otherwise the performance pattern was quite similar. This suggests that the concrete/ abstract (nameable/non-nameable) distinction had no crucial impact except that, unsurprisingly, the concrete stimuli were somewhat better retained. Test pairs with at least one frequent stimulus were responded to correctly at well above chance level ( $p$ s $<$ $0.01)$, that is in the $f_{r} 0 s_{w} O, f_{r} 0 f_{w} 0, s_{w} O f_{w} O, f_{r} 0 n_{w} O$, and $\mathrm{n}_{\mathrm{r}} \mathrm{O} \mathrm{f}_{\mathrm{w}} \mathrm{O}$ pairs the frequent right stimuli were approached and/or the frequent wrong stimuli were avoided. With the $\mathrm{s}_{\mathrm{r}} \mathrm{O} \mathrm{s}_{\mathrm{w}} \mathrm{O}$ pairs, choices occurred at chance level with abstract pairs, but at above chance level $(p<0.01)$ with the concrete pairs. Combinations of $\mathrm{s}$ and $\mathrm{n}$ stimuli yielded increased errors. With concrete stimuli, error rates for the $n_{r} O s_{w} O$ pairs were still below chance level $(p<0.05)$, but not so for $\mathrm{s}_{\mathrm{r}} \mathrm{O} \mathrm{n}_{\mathrm{w}} \mathrm{O}$ pairs; with the abstract pairs both pair types were responded to randomly. With concrete $\mathrm{n}_{\mathrm{r}} \mathrm{O} \mathrm{s}_{\mathrm{w}} \mathrm{O}$ pairs the somewhat familiar $\mathrm{s}_{\mathrm{w}}$ stimuli were in fact preferred to the $\mathrm{n}_{\mathrm{r}}$ stimuli $(p<0.01)$. The mean reaction times were generally in concordance with the error rates in that larger error rates were mostly associated with longer reaction times across the various types of pairs (Figure 5, lower panel).

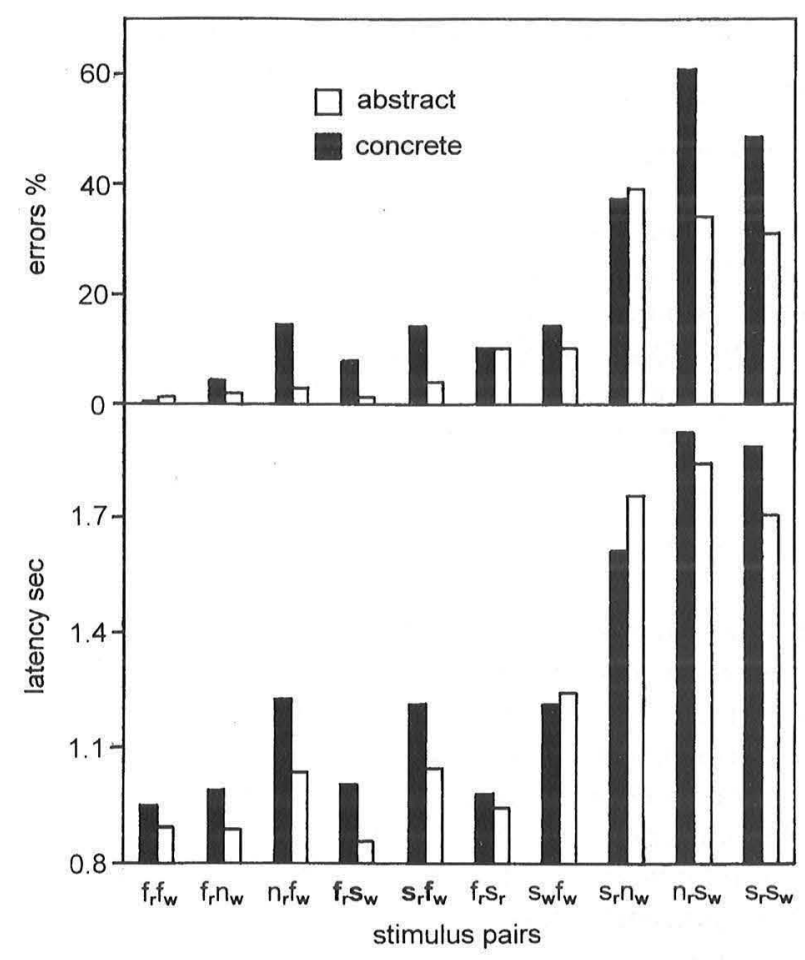

Figure 5. Experiment 3. Mean error rates (above) and averaged median latencies (below) during test phase for abstract and concrete test pairs and training pairs. The first stimulus of each pair was deemed correct (see text). The pairs are ordered along a theory-derived, decreasing interstimulus distance dimension explained later in the Discussion.

The mean subjective frequency ratings for the different stimulus types are shown in Figure 6. They were slightly higher for concrete than for abstract stimuli throughout, except for novel stimuli. Because of pre-experimental experience with them, the concrete stimuli were arguably more familiar to the subjects than the abstract stimuli, and this presumably caused them to overrate them. The objectively frequent stimuli were judged as having been presented more often than objectively scarce stimuli, which in turn were judged as more frequent than the objectively even more rarely presented novel stimuli. Ad-

Table 5. Experiment 3: Mean Number of Presentations and Reinforcements Per Stimulus for $f_{r}, f_{w}, s_{r}$ and $s_{w}$ Type Stimuli During the Training Phase

\begin{tabular}{lcccc}
\hline Pair type & Present $\mathrm{r}$ & Reinforce $\mathrm{r}$ & Present $\mathrm{w}$ & Reinforce $\mathrm{w}$ \\
\hline $\mathrm{f}_{\mathrm{r}}+\mathrm{s}_{\mathrm{w}}-$ abstr. & 21.4 & +16.8 & 3.6 & -0.8 \\
$\mathrm{f}_{\mathrm{r}}+\mathrm{S}_{\mathrm{w}}-$ concr. & 21.4 & +18.8 & 3.6 & -0.5 \\
$\mathrm{~S}_{\mathrm{r}}+\mathrm{f}_{\mathrm{w}}-$ abstr. & 3.6 & +2.3 & 21.4 & -7.8 \\
$\mathrm{~S}_{\mathrm{r}}+\mathrm{f}_{\mathrm{w}}-$ concr. & 3.6 & +2.9 & 21.4 & -4.0 \\
\hline
\end{tabular}




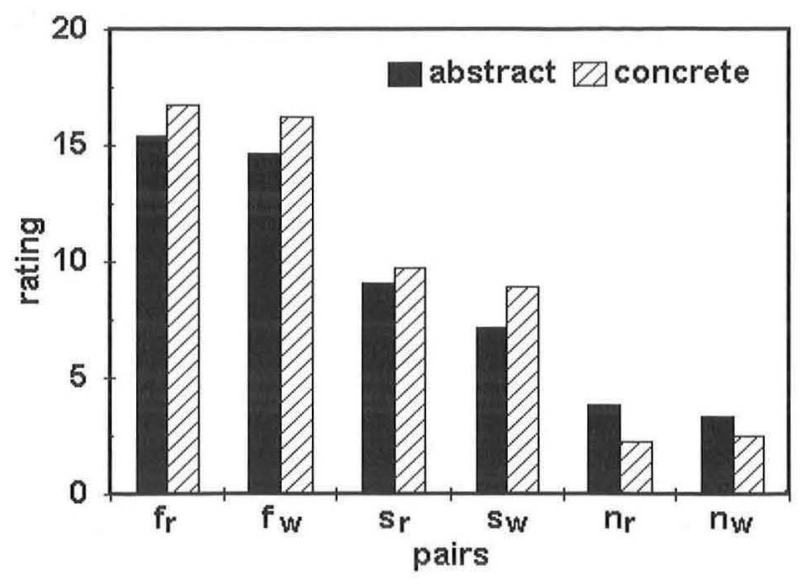

Figure 6. Experiment 3: Mean frequency ratings for abstract and concrete stimuli.

ditionally, given equal presentation frequencies, $r$ stimuli were subjectively judged as somewhat more frequent than $\mathrm{w}$ stimuli were. The frequency ratings agreed significantly with a $\mathrm{f}_{\mathrm{r}}>\mathrm{f}_{\mathrm{w}}>\mathrm{s}_{\mathrm{r}}>\mathrm{s}_{\mathrm{w}}>\mathrm{n}$ ranking for both types of stimulus (Page-tests: abstract, $p<0.01$; concrete, $p<0.01$ ).

\section{Discussion}

\section{Verbal-Pictorial Comparison}

Hardly any research has hitherto looked into the question of whether pictorial list discrimination learning results do or do not replicate verbal list discrimination findings (Goulet \& Sterns, 1970; Rowe, 1973). Pictorial stimuli have properties that differ from those of verbal stimuli. The latter are characterized by the fact that they are nearly automatically converted from a visual (read words or syllables) or an auditory code (heard words or syllables) into a phonological code (spoken words or syllables). Pictures are far less readily converted from a visual code (seen patterns) into a phonological code (spoken or almost spoken words), or indeed into any ouput code (imagined or drawn patterns). Of course, the difference is not absolute as meaningful pictograms may be processed mainly verbally and nonsense syllables may be processed mainly visually. For the first two experiments we used picture stimuli that were abstract visual patterns selected to be difficult to name and thus unlikely to be processed in any verbal mode. Nevertheless, the results of Experiment 1 and 2 yielded results that were at least broadly reminiscent of those obtained in verbal discrimination experiments (Underwood et al., 1964; Ekstrand et al. 1966).
In Experiment 3 concrete, easily nameable and abstract, hardly nameable stimuli were compared. Generally, learning proceeded faster with concrete stimuli and also the test performance for concrete stimulus pairs was somewhat more superior to the abstract stimuli. Nevertheless, the patterns of results were quite similar, indicating that the naming probably evoked by the concrete stimuli did not fundamentally alter the processes involved in pictorial list discrimination learning except generally facilitating it. This suggests that despite different styles of stimulus coding there may be close parallels between pictorial and verbal list discrimination learning processes.

\section{Univariate Frequency Account}

We now turn to the various explanatory accounts beginning with sheer frequency theory. During the 1st list learning in Experiment 1, group R experienced the $\mathrm{r}$ stimuli more often than group $\mathrm{W}$ did the $\mathrm{w}$ stimuli (Table 2). If subjects based their choices only on the presentation frequencies, the group $\mathrm{R}$ should have performed better than group $\mathrm{W}$ when switched to the 2nd list where the complementary stimuli were in both cases zero frequency $n$ stimuli, but that did not occur (Figure 2). In Experiment 2, group R experienced the $\mathrm{r}$ stimuli less often than group $\mathrm{W}$ did the w stimuli (Table 3). Here one would expect group R to perform worse than group $\mathrm{W}$ when switched to 2nd list pairs (Figure 3). But on the contrary, group $\mathrm{R}$ did somewhat better than group $\mathrm{W}$.

Table 4 assembles the relevant information for Experiment 3. Since the differences between stimulus frequencies only allowed for relative predictions about stimulus choices, these differences were converted into the percent correct choices. The relationship between the calculated difference and the observed choice percentage belonging to one of the stimulus pair types served as scaling anchors for all the other pair types. The computations proceeded according to the formula $\left.\mathrm{c}_{\mathrm{xy}}=\left(\mathrm{d}_{\mathrm{xy}} *\left(\mathrm{c}_{\mathrm{ab}}-50\right) / \mathrm{d}_{\mathrm{ab}}\right)\right)+$ 50. The $\mathrm{c}_{\mathrm{xy}}$ term is the estimated percent choices correct for a pair x y, calculated (i) on the basis of its frequency difference $d_{x y}$, (ii) proportionally to the percentage $c_{a b}$ and the corresponding difference $d_{a b}$ of an anchor pair a b, while (iii) taking into consideration that any difference $d_{x y}=0$ is equivalent to a $\mathrm{c}_{\mathrm{xy}}=50 \%$ choices correct. Because on general grounds the largest empirical difference is likely to be that proportionally least affected by statistical noise, the frequency difference and percent choice correct of pair $\mathrm{f}_{\mathrm{r}} \mathrm{n}_{\mathrm{w}}$ were used as scaling anchors. What stands out against the univariate frequency account is that with $f_{r} f_{w}$ pairs, subjects should have chosen at chance levels since they could not have 
Table 4. Experiment 3: Observed Choice Percentages of First Stimulus of Pairs Listed (Averages of Abstract and Concrete Pair Scores) and Predicted Choice Percentages According to the Frequency and to the Reinforcement Accounts

\begin{tabular}{llcclcrrr}
\hline Pair types & $\begin{array}{c}\text { Observed } \\
\text { choices }\end{array}$ & \multicolumn{2}{c}{ Reinf./freq. differences } & \multicolumn{2}{c}{ Predicted choices } & \multicolumn{2}{c}{ Differences obs./pred. } \\
\hline 1 & 2 & $\%$ acc. & Freq. & Reinf. & Freq. & Reinf. & Freq. & Reinf. \\
$\mathrm{f}_{\mathrm{r}}$ & $\mathrm{f}_{\mathrm{w}}$ & $99.1^{*}$ & 0.0 & $23.6^{*}$ & 50.0 & 99.1 & -49.1 & +0.0 \\
$\mathrm{f}_{\mathrm{r}}$ & $\mathrm{n}_{\mathrm{w}}$ & $96.9^{*}$ & $21.4^{*}$ & 17.8 & 96.9 & 86.9 & 0.0 & -10.0 \\
$\mathrm{f}_{\mathrm{r}}$ & $\mathrm{S}_{\mathrm{w}}$ & 95.4 & 17.9 & 18.4 & 89.1 & 88.2 & -6.3 & -7.2 \\
$\mathrm{f}_{\mathrm{r}}$ & $\mathrm{S}_{\mathrm{r}}$ & 90.2 & 17.9 & 15.2 & 89.1 & 81.6 & -1.1 & -8.6 \\
$\mathrm{n}_{\mathrm{r}}$ & $\mathrm{f}_{\mathrm{w}}$ & 91.5 & 21.4 & 5.9 & 96.9 & 62.2 & +5.4 & -29.3 \\
$\mathrm{~S}_{\mathrm{r}}$ & $\mathrm{f}_{\mathrm{w}}$ & 91.0 & 17.9 & 8.4 & 89.1 & 67.5 & -1.9 & -23.5 \\
$\mathrm{~S}_{\mathrm{w}}$ & $\mathrm{f}_{\mathrm{w}}$ & 88.4 & 17.9 & 5.2 & 89.1 & 60.9 & +0.7 & -27.5 \\
$\mathrm{~S}_{\mathrm{r}}$ & $\mathrm{S}_{\mathrm{w}}$ & 60.7 & 0.0 & 3.2 & 50.0 & 56.7 & -10.7 & -4.0 \\
$\mathrm{~S}_{\mathrm{r}}$ & $\mathrm{n}_{\mathrm{w}}$ & 62.5 & 3.6 & 2.6 & 57.8 & 55.4 & -4.7 & -7.1 \\
$\mathrm{n}_{\mathrm{r}}$ & $\mathrm{S}_{\mathrm{w}}$ & 52.7 & 3.6 & 0.6 & 57.8 & 51.3 & +5.1 & -1.4 \\
\hline
\end{tabular}

Note. The differences between observed and predicted choice scores are also listed. Entries marked with * served as alternative scaling anchors (see text).

discriminated the stimuli solely on the basis of their presentation frequency differences, but, in fact, the discrimination performance on these test pairs was almost perfect (Figure 5).

\section{Univariate Reinforcement Account}

In Experiment 1, during the learning of the 1st list, group $\mathrm{R}$ obtained more rewards per $\mathrm{r}$ stimulus than group $\mathrm{W}$ obtained penalties per $\mathrm{w}$ stimulus (Table 2 ). The relatively worse 2 nd list performance of group W (Figure 2) could thus be explained in terms of this factor. In Experiment 2 group $\mathrm{R}$ again obtained more rewards per $\mathrm{r}$ stimuli than group $\mathrm{W}$ obtained penalties per $\mathrm{w}$ stimuli (Table 4). The W group should thus have performed worse than the $\mathrm{R}$ group when switched to the 2nd list, but the opposite happened.

The applicability of the reinforcement account to the results of Experiment 3 was examined in a manner analogous to that described above but employing, of course, the reinforcement difference scores. Because here pair $\mathrm{f}_{\mathrm{r}} \mathrm{f}_{\mathrm{w}}$ offered the largest empirical distance, it was used as scaling anchor. The relevant information is assembled in Table 4. The reinforcement theory predictions badly underestimate the empirical choice scores connected with three of the four pairs containing the $\mathrm{f}_{\mathrm{w}}$ stimuli.

\section{Bivariate Theory}

It is patent that accounts which focus exclusively on either the frequency or the reinforcement variable do not succeed in satisfactorily predicting the empirical choices scores. This circumstance already led Ekstrand et al. (1966a) to formulate a verbally expressed composite theory. Pursuing the same idea, Estes (1976) developed a mathematical model that took into account the ratio of right and wrong choices and the ratios of presentation frequencies to predict the choices of given stimuli. However, his model is exceedingly complex, involving several free parameters, and this may be why, as far as we know, it has never been used again.

We incorporated the frequency-reinforcement combination principle into a far simpler model. Stimulus presentation frequencies and stimulus reinforcement numbers are thought of as mapping on a pair of orthogonal co-ordinates which define a plane wherein the various kinds of stimuli of a list experiment can be located (Figure 7). The geometrically shortest, scalar distance between any two such stimulus loci can be thought as representing the discriminability of these stimuli. This framework is reminiscent of that used in models which relate the multidimensional similarity between stimuli and their behavioral discriminability (Shepard, 1987; Nosofsky, 1992). In our case the ordinate has been selected to represent the empirical number of rewards $(+v)$ or the number of penalties $(-v)$ arising from choices of a given type of stimulus and the abscissa has been selected to represent the number of presentations $(h)$ involving the same type of stimulus. Within these Cartesian coordinates the Euclidian distance $\left(d_{\mathrm{xy}}\right)$ between any two stimulus types, $\mathrm{x}$ and $\mathrm{y}$, is given by the Pythagorean formula $d_{\mathrm{xy}}={ }^{2} \sqrt{ }\left(\left(h_{\mathrm{x}}-h_{\mathrm{y}}\right)^{2}+\left(v_{\mathrm{x}}-\right.\right.$ $\left.v_{y}\right)^{2}$ ). It is additionally specified that, within a given pair, the stimulus with a larger $v$ is chosen in preference over one with a lesser $v$, and that if two stimuli 
have the same $v$, the one with the higher $h$ should be chosen. The former rule reflects the precedence of reinforcement already recognized by Ekstrand et,al. (1966) and the latter rule reflects the subsidiary impact of the exposure effect identified by Zajonc (1968). The distances are otherwise converted to correct choice percentages according to analogues of the formula and anchoring procedure specified earlier in connection with Table 6 .

\section{Model Adequacy}

In Experiment 1, all groups learned the same 1st list of stimulus pairs. The $\mathrm{C}$ group received a 2 nd list composed of completely new stimuli, thus the 1 st list history should play no role. But group R preexperienced the $\mathrm{r}$ stimuli and group $\mathrm{W}$ the $\mathrm{W}$ stimuli of the 2 nd list while learning the 1st list. The corresponding numbers of presentations and reinforcements taken from Table 2 are shown plotted in Figure 7. The novel stimuli that had no previous presentation or reinforcement history are shown plotted at the coordinate's origin. The scalar distance between $\mathrm{r}$ and $\mathrm{n}$ stimuli for group $\mathrm{R}$ was calculated as being 10.6 , the distance between $\mathrm{n}$ and $\mathrm{w}$ stimuli for group $\mathrm{W}$ as being 7.9, while that between the $\mathrm{n}$ stimuli of group $\mathrm{C}$ was obviously zero. Thus the group $\mathrm{R}$ does relatively better with the 2 nd list than the group W does, and the latter again does better than the $\mathrm{C}$ group. Using the distance and performance of group $\mathrm{R}$ for anchoring, the choice performance for group $\mathrm{W}$ was predicted to be $69.9 \%$ (observed $59.4 \%$ ) and that for group $\mathrm{C}$ to be $50.0 \%$ (observed $53.0 \%$ ).

In Experiment 2 the w stimuli were shown twice as frequently as the $r$ stimuli during 1 st list training. The number of presentations and reinforcements that

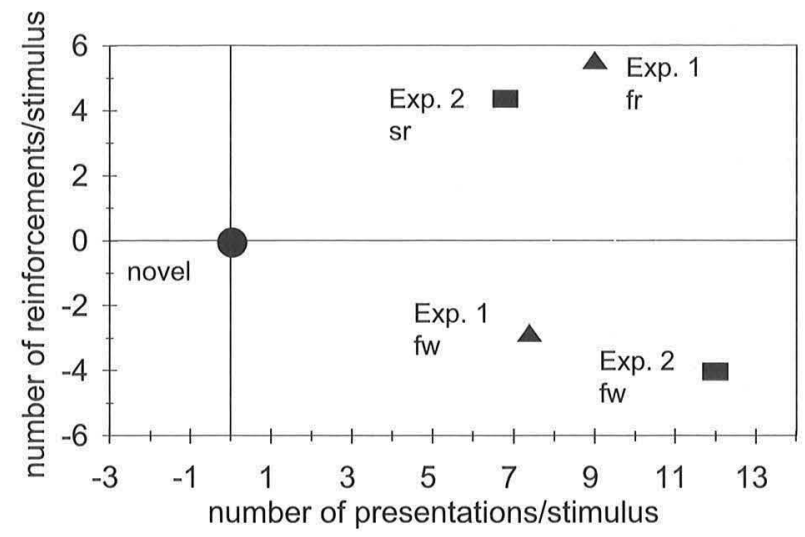

Figure 7. Experiments 1 and 2: Two-dimensional plot of number of reinforcements and number of presentations per stimulus types.

arose (Table 4) are also shown in Figure 7. The scalar distance between $\mathrm{r}$ and $\mathrm{n}$ stimuli for group $\mathrm{R}$ was now 8.1 and that between $\mathrm{w}$ and $\mathrm{n}$ stimuli for group $\mathrm{W}$ amounted to 12.6 . This agrees with the fact that group R showed about 10 percent points more errors than group W. Using the distance and percent choices correct of group W for anchoring, the predicted choice for group $\mathrm{R}$ was $72.2 \%$, which is close to the observed choice score of $74.5 \%$.

Figure 8 depicts the locations of $\mathrm{f}_{\mathrm{r}}, \mathrm{f}_{\mathrm{w}}, \mathrm{s}_{\mathrm{r}}, \mathrm{s}_{\mathrm{w}}$ and $\mathrm{n}$ stimuli according to the frequencies and reinforcement numbers listed in Table 5. The computed distances and the predicted and observed choice percentages for the various pairs are listed in Table 7. Although not separately listed in the table, the predicted and observed choice scores differed slightly less for the abstract pairs than for the concrete pairs. It is likely that the latter were affected by extra-experimental noise caused by varying experiences with

Table 7. Experiment 3: Distance Between Stimulus Types (Concrete and Abstract Averaged) During Test Phase and Predicted/Observed choices (\%)

\begin{tabular}{lccccc}
\hline \multicolumn{5}{l}{ Stimulus pairs } & \multicolumn{4}{c}{ Average concrete and abstract } \\
\hline 1 & 2 & Distance & Predicted & Observed & Obs./pred. \\
\hline $\mathrm{f}_{\mathrm{r}}$ & $\mathrm{f}_{\mathrm{w}}^{\prime}$ & 23.6 & 89.8 & 99.1 & -9.3 \\
$\mathrm{f}_{\mathrm{r}}$ & $\mathrm{n}_{\mathrm{w}}$ & $27.8^{*}$ & 96.9 & 96.9 & +0.0 \\
$\mathrm{f}_{\mathrm{r}}$ & $\mathrm{S}_{\mathrm{w}}$ & 25.6 & 93.2 & 95.4 & -2.2 \\
$\mathrm{f}_{\mathrm{r}}$ & $\mathrm{S}_{\mathrm{r}}$ & 23.4 & 89.5 & 90.2 & -0.7 \\
$\mathrm{n}$ & $\mathrm{f}_{\mathrm{w}}$ & 22.2 & 87.4 & 91.5 & -4.1 \\
$\mathrm{~S}_{\mathrm{r}}$ & $\mathrm{f}_{\mathrm{w}}$ & 19.7 & 83.3 & 91.0 & -7.7 \\
$\mathrm{~S}_{\mathrm{w}}$ & $\mathrm{f}_{\mathrm{w}}$ & 18.6 & 81.3 & 88.4 & -7.1 \\
$\mathrm{~S}_{\mathrm{r}}$ & $\mathrm{S}_{\mathrm{w}}$ & 3.2 & 55.4 & 60.7 & -5.3 \\
$\mathrm{~S}_{\mathrm{r}}$ & $\mathrm{n}_{\mathrm{w}}$ & 4.4 & 57.4 & 62.5 & -5.1 \\
$\mathrm{n}$ & $\mathrm{S}_{\mathrm{w}}$ & 3.6 & 56.1 & 52.7 & +3.4 \\
\hline
\end{tabular}

Note. Pair type $\mathrm{f}_{\mathrm{r}} \mathrm{o} \mathrm{n}_{\mathrm{w}} \mathrm{o}$ distance marked with * served as an anchor 
the corresponding everyday stimuli. Regardless, a joint consideration of stimulus and reinforcement frequencies is obviously necessary for an adequate explanation of the Experiments 3 results. In particular, whenever frequent stimuli were included in a test pair, choice performance was well above chance, but when scarce stimuli were paired with other scarce, or novel stimuli, choice performance dropped to near chance level. The overall pattern of the responses agrees significantly with that predicted by our bivariate model (Page test: $p<0.01$ ).

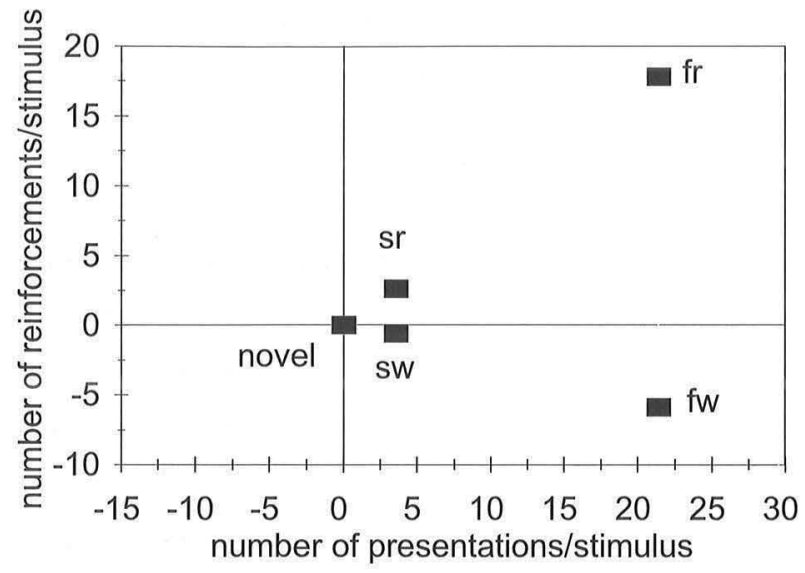

Figure 8. Experiment 3: Locations of stimulus types $\mathrm{n}, \mathrm{s}_{\mathrm{r}}, \mathrm{s}_{\mathrm{w}}, \mathrm{f}_{\mathrm{r}}$, and $\mathrm{f}_{\mathrm{w}}$, at the beginning of the test phase.

The model is in principle also applicable to the Fersen and Delius (1989) pigeon experiment described in the Introduction. Unfortunately, the precise numbers of presentations and reinforcements attaching to the various stimulus types were no longer on record at the time when the present model was developed. Nevertheless, an insertion of likely estimates into the model yielded interstimulus distances that were congruent with the ranking $\mathrm{n}_{\mathrm{r}} \mathrm{O} \mathrm{n}_{\mathrm{w}} \mathrm{O}<\mathrm{n}_{\mathrm{r}} \mathrm{O}$ $\mathrm{s}_{\mathrm{w}} \mathrm{O}<\mathrm{f}_{\mathrm{r}}+\mathrm{s}_{\mathrm{w}}-<\mathrm{f}_{\mathrm{r}} \mathrm{O} \mathrm{n}_{\mathrm{w}} \mathrm{O}$ of discrimination performances empirically found.

\section{Extensions and Comments}

Note that as it stands, the model has no free parameters that need to be adjusted. Inclusion of parameters governing, for example, the relative impact of the frequency and reinforcement variables, and, within the latter, the relative influence of rewards and penalties or even further parameters governing non-linearities affecting each of these variables, would perhaps yield better fits with the empirical data, but clearly all this would be at the cost of an increased, undesirable complexity.

More important perhaps, the model's behavior has only been assessed in relation to data coming from experiments where the presentation frequencies and reinforcement rates pertaining to the various stimuli were not totally independent. It would be instructive to examine, for example, how well the model would perform when confronted with results of experiments where stimuli $\mathrm{x}$ would be presented sometimes under either the $\mathrm{x}^{+}$, rewarded or the $\mathrm{x}_{-}^{-}$, penalized condition, and sometimes in an xo unreinforced manner, such as that used for testing in Experiment 3. The latter procedure would yield a fully independent control over the frequency variable. Excessive familiarity arising through many such presentations might, for example, lead to the onset of boredom and thus to a choice preference for novel stimuli (Fowler, 1965). This would be contrary to the preference that the mere exposure effect normally brings about for the frequent stimuli and thus strain the model. The model can also be expected to run into difficulties when serial discrimination experiments are designed, so that the novelty or familiarity attaching to the individual stimuli allows their categorization as being right or wrong (Standing, Conezio, \& Haber, 1970; Delius, 1985; Macphail \& Reilly, 1989).

\section{Conclusion}

The experimental results reported indicate that much of the same interactions between presentation frequencies and reward values that have been described as determining performance in verbal list discrimination learning by humans also intervene in visual discrimination list learning by humans. A simple model that seems to capture in a very succinct and quite accurate manner stimulus preferences of subjects' in terms of Euclidian interactions between presentation frequencies and reinforcement rates provides a heuristic framework that invites further research into the issue.

\section{References}

Bornstein, R. F. (1989). Exposure and affect: Overview and meta-analysis of research, 1968-1987. Psychological Bulletin, 106, 265-289.

Brown, N. R. (1995). Estimation strategies and the judgment of event frequency. Journal of Experimental Psychology: Learning, Memory, and Cognition, 21, $1539-1553$.

Delius, J. D. (1985). Cognitive processes in pigeons. In G. d'Ydewalle (ed.), Cognition, information processing, and motivation, pp. 3-18. Amsterdam: Elsevier.

Delius, J. D., \& Delius, J. A. M (2002). Biopsychologie des Lernens [Biopsychology of learning]. In T. Elbert \& N. Birbaumer (eds.), Biologische Grundlagen der Psychologie: Enzyklopädie der Psychologie [Biological bases of psychology: Encyclopeadia of psychology], pp. $445-$ 518. Göttingen, Germany: Hogrefe. 
Ekstrand, B. R., Wallace, W. P., \& Underwood, B. J. (1966). A frequency theory of verbal discrimination learning. Psychological Review, 73, 566-578.

Estes, W. K. (1976). The cognitive side of probability learning. Psychological Review, 1, 37-64.

Fersen von, L. \& Delius, J. D. (1989). Long-term retention of many visual patterns by pigeons. Ethology, 82, $141-$ 155.

Fowler, H. (1965). Curiosity and exploratory behavior. New York: Macmillan.

Gellermann, W. (1933). Chance orders of alternating stimuli in visual discrimination experiments. Journal of Genetic Psychology, 42, 206-208.

Goulet, L. R., \& Sterns, H. L. (1970). Verbal-discrimination learning and transfer with verbal and pictorial materials. Journal of Experimental Child Psychology, 10, $257-263$.

Hintzman, D. L., \& Curran, T. (1995). When encoding fails: instructions, feedback, and registration without learning. Memory \& Cognition, 23, 213-226.

Kausler, D. (1974). Psychology of verbal learning and memory. New York: Academic.

Macphail, E. M., \& Reilly, S. (1989). Rapid acquisition of a novelty versus familiarity concept by pigeons $(\mathrm{Co}-$ lumba livia). Journal of Experimental Psychology: Animal Behavior Processes, 15, 242-252.

Maddox, W. T., \& Estes, W. K. (1997). Direct and indirect stimulus frequency effects in recognition. Journal of Experimental Psychology: Learning, Memory and Cognition, 23, 539-559.

McClelland, D. C. (1942). Studies in serial verbal discrimination learning. II. Retention of responses to right and wrong words in a transfer situation. Journal of Experimental Psychology, 31, 149-162.

Melsbach, G., \& Delius, J. D. (2003). Reizhäufigkeiten und Reizwertigkeiten beim Lernen über visuelle Reize [Stimulus frequency and stimulus value while learning about visual stimuli]. Manuscript in preparation.

Murphy, S. T., Monahan, J. L., \& Zajonc, R. B. (1995). Additivity of nonconscious affect: combined effects of priming and exposure. Journal of Personality and Social Psychology, 69, 589-602.

Nosofsky, R. M. (1992). Similarity scaling and cognitive process models. Annual Review of Psychology, 43, 2553.

Ogus, A. L., \& May, W. W. (1978). An examination of the rule-use construct of the frequency theory of verbal discrimination learning. Journal of General Psychology, 99, 93-97.
Reber, R., Winkielman, P., \& Schwartz, N. (1998). Effects of perceptual fluency on affective judgements. Psychological Science, 9, 45-50.

Rowe, E. J. (1973). Verbalization effects in discrimination learning of pictures and words. Canadian Journal of Psychology, 27, 184-190.

Shepard, R. N. (1987). Toward a universal law of generalization for psychological science. Science, 237, $1317-$ 1323.

Siemann, M., \& Delius, J. D. (1998). Algebraic learning and neural network models for transitive and nontransitive responding. European Journal of Cognitive Psychology, 10, 307-334.

Standing, L., Conezio, J., \& Haber, R. J. (1970). Perception and memory for pictures, single trial learning of 2500 visual stimuli. Psychonomic Science, 19, 73-74.

Underwood, B. J., \& Freund, J. S. (1968). Two tests of a theory of verbal-discrimination learning. Canadian Journal of Psychology, 22, 96-104.

Underwood, B. J., Jesse, F., \& Ekstrand, B. R. (1964). Knowledge of rights and wrongs in verbal-discrimination learning. Journal of Verbal Learning and Verbal Behavior, 3, 183-186.

Watkins, M. J., Peynircioglu, Z. F., \& Brems, D. J. (1984). Pictorial rehearsal. Memory and Cognition, 12, 553557.

Weiner, B. (1992). Human motivation: Metaphors, theories, and research. Newbury Park, CA: Sage.

Zajonc, R. B. (1968). Attitudinal effects of mere exposure. Journal of Personality and Social Psychology: Monographs, 9, 1-27. Thousand Oaks, CA: Sage.

Zechmeister, R. B., \& Nyberg, S. E. (1986). Human memory. An introduction to research and theory. Monterey, CA: Brooks/Cole.

Received October 1, 2002

Revision received December 2, 2002

Accepted December 19, 2002

Dr. Juan D. Delius

Experimental Psychology

University of Konstanz

D-78457 Konstanz

Germany

Tel: +497531883184

Fax: +49 7531883164

E-mail: juan.delius@uni-konstanz.de 